\title{
Regressions of Length and Width to Predict Arthropod Biomass in the Hawaiian Islands ${ }^{1}$
}

\author{
Daniel S. Gruner ${ }^{2}$
}

\begin{abstract}
Biologists in many fields use published regression equations to predict biomass from simple linear body measurements. Power functions are used with arthropods, facilitating biomass estimation of a sample when destructive techniques are not feasible. Resulting predictive coefficients vary widely depending on region and taxa. There are no published biomass regressions for oceanic island fauna, despite the widely accepted conclusion that their arthropod assemblages are unusual in composition. I present a suite of general and taxonomically and morphologically restricted regression equations developed for arthropods in the Hawaiian Islands. General regression equations were highly significant when only length was used to predict biomass, but fits were usually improved by including body width. In regressing restricted sets of taxa, the addition of width did little to improve the fit of the functions. Thus, the choice of regression equations involves a trade-off in taxonomic resolution: precise biomass estimates will come either from (1) low taxonomic resolution measured for both length and width, or (2) high taxonomic resolution measured only for body length. These equations have a high predictive capacity for a broad range of arthropod taxa common in the Hawaiian Islands and, in the absence of locally developed equations, the arthropods of other oceanic islands.
\end{abstract}

The SHEER ABUNDANCE and diversity of arthropods in terrestrial ecosystems attest to their importance in ecosystem function. A number of applications require the estimation of arthropod biomass in ecosystems, from testing of classic hypotheses of biomass ratios in trophic groups (Hairston et al. 1960) and description of macroecological patterns

${ }^{1}$ Specimens were collected during research supported by NSF DGE-9355055 and DUE-9979656 to the Center for Conservation Research and Training of the University of Hawai'i at Mānoa, the John D. and Catherine T. MacArthur Foundation, the Science to Achieve Results (STAR) program of the U.S. Environmental Protection Agency, Sigma $\mathrm{Xi}$, the Hawai'i Audubon Society, the ARCS Foundation, and the NSF Doctoral Dissertation Improvement Granting program. Manuscript accepted 19 December 2002.

2 Department of Zoology and Ecology, Evolution and Conservation Biology Graduate Program, University of Hawai'i at Mānoa, 2538 The Mall/Edmondson Hall, Honolulu, Hawaiti 96822 (phone: 808-735-3983; fax: 808-956-9812; E-mail: dgruner@hawaii.edu).

Pacific Science (2003), vol. 57, no. 3:325-336

(C) 2003 by University of Hawai'i Press

All rights reserved
(Brown and Maurer 1986, Blackburn et al. 1993, Blackburn and Gaston 1997) to the availability of food resources for birds (Hódar 1997) or other vertebrates (Sage 1982). Arthropods can be weighed directly while fresh or subsequent to freezing. However, fresh biomass measurements are sensitive to the conditioning of the sample, local relative humidity, or any factor that influences the water content of specimens. More often, researchers collect a large quantity of material in a short time and must preserve specimens for identification and analysis at a later date. These specimens can then be dried and weighed in bulk to eliminate the variable influence of body water content but at the price of destruction of soft-bodied arthropods and any ability to identify and voucher them.

A preferred approach to biomass estimation is to use general or taxonomically restricted regression relationships to predict arthropod biomass from easily obtained length and/or width measurements (Rogers et al. 1976, 1977, Schoener 1980, Sage 1982, Gowing and Recher 1984, Sample et al. 1993, Hódar 1996). Using power functions, these 
equations reduce the effort required to estimate biomass of a sample when destructive techniques are not feasible. But which regression coefficients to use? Significant statistical differences among compared equations appear to be rare (Gowing and Recher 1984, Sample et al. 1993). However, Hódar (1996) compared nine published lengthweight regression relationships and found their performance highly variable in comparison with the actual known biomass of samples. Several authors emphasized the increased precision obtained with equations specific to lower taxonomic groupings (Gowing and Recher 1984, Hódar 1996). Even among specific groups, Schoener (1980) noticed differences in parameter estimates of tropical versus temperate insects and suggested hypotheses why there might be systematic differences in the faunas to explain this pattern.

The arthropod fauna of the Hawaiian Islands is widely cited as disharmonic and locally depauperate relative to other tropical areas as a result of its extreme isolation from sources of colonizing lineages (Zimmerman 1948, Howarth 1990). The most common groups in these Islands may not be well represented in regression equations developed elsewhere. In addition, shifts to smaller or larger forms are common in the evolution of endemic species on islands (Whittaker 1998). It is not known to what extent these size changes alter the allometric relations of linear measurements to body mass. Thus, it is not at all clear which published length-weight relationships are most applicable to estimation of arthropod biomass on tropical island ecosystems. Recent investigations into the diet of endangered birds required biomass equations, but equations specific to Hawai ${ }^{6} i$ were unavailable (Peck 1993, Fretz 2000). Because the assessment of the most appropriate published equations may have proven as laborious as generating new ones, I sought to remedy this lack. I present a suite of taxonomically general and specific regression equations developed through the course of ongoing work in the Hawaiian Islands. Beyond their immediate utility, it is hoped that the biomass equations will benefit future work focused on Pacific island fauna.

\section{MATERIALS AND METHODS}

\section{Field and Laboratory}

I selected specimens as available within incidental or nonquantitative collections obtained over the course of other work in the Hawaiian Islands from 1996 to 2001 . With few exceptions, specimens were collected from the endemic tree Metrosideros polymorpha Gaudichaud-Beaupré (Myrtaceae). Metrosideros is a common genus throughout the Pacific to New Zealand (Mueller-Dombois and Fosberg 1998), but it is particularly abundant and widespread in the Hawaiian Islands (Dawson and Stemmerman 1990). The arthropod fauna of this tree is particularly diverse among Hawaiian trees (Southwood 1960), representing a number of lineages (Stein 1983). Thus it is a reasonable first approximation for arthropod biomass predictions in the Hawaiian Islands and, perhaps, Pacific islands more generally. I collected arthropods through pyrethrum canopy fogging (Gruner and Polhemus in press), branch clipping, vegetation beating, malaise trapping, and hand collecting at sites on Hawai ${ }^{\prime} i$, Moloka'i, O'ahu, and Kaua'i (Appendix 1). Several texts provide detail on these collection methods (New 1998, Southwood and Henderson 2000, Toda and Kitching 2002). Most collections were from intact, predominantly native forest ecosystems at elevations above $1000 \mathrm{~m}$.

All specimens were stored in $70 \%$ ethanol and measured directly upon removal from preservative. Alcohol may distort some specimens, especially in soft-bodied groups such as Lepidoptera and Araneae. Storing of specimens in alcohol also may result in extraction of some body materials (Rogers et al. 1976). Ethanol is, however, the arthropod preservative of choice for many practitioners in various fields. These regressions, then, will apply to data most easily obtained and widely available. If biomass is indeed lost during ethanol storage, the regression estimates of biomass will be conservative (Gowing and Recher 1984). 
Specimens were chosen to represent a range of taxa, sexes, life stages, and sizes as available in the incidental collections. As noted by Hódar (1996), it is of greater importance to represent the full range of variation in the estimation procedure than to randomize specimen selection. Only undamaged specimens were selected. Specimens were identified to species where possible. Otherwise, specimens were assigned to Operational Taxonomic Units (OTU) or "morphospecies" within the finest taxonomic classification obtainable.

Length was measured using a dissecting microscope with an ocular micrometer to $0.05 \mathrm{~mm}$ precision. Body length included the tip of the abdomen to the end of the head or carapace, excluding mouthparts, genitalia, ovipositors, antennae, or spinnerets (spiders). Width was measured at the widest point of the mesothorax. For nonhexapods, width was taken as the widest body segment. After morphometric measurement, specimens were then dried for $24 \mathrm{hr}$ in an oven at $70^{\circ} \mathrm{C}$ and weighed to the nearest $0.01 \mathrm{mg}$. Where possible, at least 10 specimens of a particular OTU were measured and weighed, but more than 10 often does not improve precision as long as specimens cover the range of variation in the OTU (Hódar 1996). For hemimetabolous arthropods, additional specimens were measured and weighed for life stages that differed appreciably, and for holometabolous species, for each unique life form. Extremely small specimens were weighed in groups of 2-10, lengths and widths averaged, and applied to total group mass divided by the number of individuals used.

\section{Statistical Analyses}

General and specific linear regressions were created to predict biomass of arthropods from length and width. General equations contained a large number of specimens grouped at the class level or above. Specific equations were created on restricted taxonomic lines but also on morphological similarities. For instance, Tetragnatha spiders, generally long and slender, were calculated separate from other spiders, and several families of beetles and genera of Heteroptera were isolated on the same rationale. Following other authors (Rogers et al. 1977), I used a power model to describe the size-weight relationships. The model takes the form:

$$
y=a(x)^{b}
$$

where $y=\mathrm{dry}$ biomass; $x=$ size measurement, whether length or length * width; $a$ and $b$ are coefficients estimated in the regression procedure. Morphometric and weight data were transformed to natural logarithms for analysis using linear regressions:

$$
\ln (y)=\ln (a)+b * \ln (x)
$$

Logarithmic transformations reduced heteroscedasticity in the data in accordance with statistical assumptions. Data were analyzed with linear regressions using the Systat statistical software package (Systat 2000). I ran regressions both on length and length * width and back-transformed the data for parameter estimations. Other authors have applied Bonferroni corrections because of the high number of regression equations developed (e.g., Sample et al. 1993, Hódar 1996). However, because I am not testing the null hypothesis that length (or length and width) is related to mass, I argue it is not necessary to control for the Type I error rate. Nevertheless, I apply the most conservative fixed Bonferroni correction to test the strength of the relationships (overall $\alpha=0.05$ ).

\section{RESULTS}

I measured length and width of 619 individual arthropods, from which I obtained 488 measures of biomass. Of these specimens, 431 specimens were measured individually for morphometrics and biomass, and 188 additional smaller-sized specimens were lumped into 57 groups of 2-10 individuals. Specimens were gathered from 14 arthropod orders in the subphylum Crustacea and in the classes Arachnida and Insecta (Brusca and Brusca 1990). The measured arthropods ranged from lengths of 0.65 (Acari) to 17.6 $\mathrm{mm}$ (Coleoptera: Curculionidae) and widths 


\section{TABLE 1}

Descriptive Data and Parameter Estimates for Arthropod Length $(L)$ and Length $* W i d t h(L * W)$ Regressions on Dry Biomass. Taxa Are Listed as Nested (Indented) Sets, Not Necessarily Reflecting Phylogenetic Distance with Consistent Depth of Indentation. Parameters Apply to the Relation $y=a(x)^{b}$, Where $x$ Is $\mathrm{L}$ or $\mathrm{L} * \mathrm{~W}$, and $y$ Is Mass. Linear Measurements Are in Millimeters and Mass Is in Units of Milligrams. N Refers to the Number of Insects

Measured for Length and Width; $\mathbf{n}$ Is the Number Used in Statistical Procedures after Lumping of Small Specimens for Weighing. Minimum and Maximum Length Values Are from the Statistical n. All Regressions Are Significant below the 0.001 Level Unless Otherwise Noted; Standard Errors of Estimates Are in Appendix 2.

\begin{tabular}{|c|c|c|c|c|c|c|c|c|c|c|c|}
\hline \multirow[b]{2}{*}{ Taxon } & \multirow[b]{2}{*}{ Stage } & \multirow[b]{2}{*}{$\mathrm{N}$} & \multirow[b]{2}{*}{$\mathrm{n}$} & \multirow[b]{2}{*}{ Min } & \multirow[b]{2}{*}{$\operatorname{Max}$} & \multicolumn{3}{|c|}{ L Model } & \multicolumn{3}{|c|}{$L * W$ Model } \\
\hline & & & & & & $a$ & $b$ & $R^{2}$ & $a$ & $b$ & $R^{2}$ \\
\hline Arthropoda & All & 619 & 488 & 0.90 & 17.60 & 0.0340 & 2.191 & 0.773 & 0.0929 & 1.330 & 0.890 \\
\hline Arthropoda & $\ddagger$ & 596 & 465 & 0.90 & 17.60 & 0.0288 & 2.355 & 0.808 & 0.0959 & 1.323 & 0.889 \\
\hline Insecta & All & 591 & 462 & 0.90 & 17.60 & 0.0350 & 2.173 & 0.762 & 0.0920 & 1.333 & 0.884 \\
\hline Insecta & $t$ & 570 & 439 & 0.90 & 17.60 & 0.0291 & 2.355 & 0.799 & 0.0923 & 1.346 & 0.888 \\
\hline Crustacea & All & 26 & 26 & 2.35 & 13.90 & 0.0138 & 2.669 & 0.918 & 0.0711 & 1.322 & 0.936 \\
\hline Isopoda & All & 16 & 16 & 2.35 & 13.90 & 0.0152 & 2.770 & 0.974 & 0.0578 & 1.351 & 0.943 \\
\hline Amphipoda & All & 10 & 10 & 3.75 & 10.65 & 0.0088 & 2.682 & 0.989 & 0.0723 & 1.419 & 0.976 \\
\hline Arachnida & All & 69 & 46 & 0.90 & 7.40 & 0.0562 & 2.332 & 0.895 & 0.1377 & 1.355 & 0.940 \\
\hline Araneae & All & 52 & 43 & 1.55 & 7.40 & 0.0433 & 2.532 & 0.882 & 0.1261 & 1.408 & 0.930 \\
\hline Non-Tetragnathidae & All & 39 & 30 & 1.55 & 7.40 & 0.0332 & 2.924 & 0.929 & 0.1241 & 1.418 & 0.926 \\
\hline $\begin{array}{l}\text { Tetragnathidae } \\
\text { (Tetragnatha) }\end{array}$ & All & 13 & 13 & 2.15 & 6.20 & 0.0372 & 2.406 & 0.929 & 0.1379 & 1.356 & 0.933 \\
\hline Blattodea & $\mathrm{All}$ & 18 & 18 & 2.55 & 11.20 & 0.0313 & 2.358 & 0.955 & 0.0837 & 1.387 & 0.963 \\
\hline Hymenoptera & Adult & 34 & 22 & 1.20 & 7.50 & 0.0139 & 2.383 & 0.918 & 0.0895 & 1.298 & 0.930 \\
\hline Orthoptera & All & 21 & 20 & 2.65 & 10.35 & 0.0180 & 2.720 & 0.919 & 0.1228 & 1.325 & 0.945 \\
\hline Psocoptera & All & 40 & 18 & 1.50 & 3.15 & 0.0136 & 3.115 & 0.786 & 0.0877 & 1.352 & 0.746 \\
\hline Coleoptera & All & 137 & 130 & 1.45 & 17.60 & 0.0336 & 2.347 & 0.771 & 0.1011 & 1.358 & 0.847 \\
\hline Coleoptera & Adult & 130 & 123 & 1.45 & 17.60 & 0.0339 & 2.384 & 0.801 & 0.1059 & 1.355 & 0.859 \\
\hline Carabidae & Adult & 16 & 16 & 4.10 & 16.30 & 0.0168 & 2.752 & 0.969 & 0.1200 & 1.393 & 0.970 \\
\hline Ciidae + Scolytidae & Adult & 18 & 13 & 1.45 & 2.40 & 0.0313 & 2.531 & 0.736 & 0.1083 & 1.480 & 0.898 \\
\hline Ciidae & Adult & 14 & 9 & 1.45 & 2.45 & 0.0247 & 3.102 & $0.757^{*}$ & 0.1144 & 1.637 & 0.875 \\
\hline Coccinellidae & Adult & 12 & 12 & 1.55 & 4.05 & 0.0724 & 2.665 & $0.651^{*}$ & 0.1873 & 1.189 & 0.560 \\
\hline Nitidulidae & Adult & 22 & 22 & 3.00 & 4.50 & 0.0679 & 1.308 & $0.384^{\star}$ & 0.0719 & 1.103 & 0.586 \\
\hline (Slender beetles ${ }^{a}$ ) & Adult & 21 & 17 & 1.65 & 10.30 & 0.0138 & 2.595 & 0.959 & 0.1092 & 1.213 & 0.962 \\
\hline (All weevils ${ }^{b}$ ) & Adult & 43 & 43 & 2.10 & 17.60 & 0.0310 & 2.641 & 0.887 & 0.1363 & 1.379 & 0.880 \\
\hline Aglycyderidae (Proterbinus) & Adult & 19 & 19 & 2.10 & 4.05 & 0.0183 & 3.144 & 0.974 & 0.1295 & 1.481 & 0.973 \\
\hline Anobiidae & Adult & 7 & 7 & 3.35 & 4.45 & 0.0080 & 3.463 & $0.731^{* *}$ & 0.0769 & 1.422 & $0.820^{\star}$ \\
\hline Curculionidae & Adult & 17 & 17 & 2.50 & 17.60 & 0.0607 & 2.315 & 0.781 & 0.1915 & 1.298 & 0.796 \\
\hline Heteroptera & All & 55 & 55 & 2.10 & 9.55 & 0.0411 & 1.934 & 0.823 & 0.0843 & 1.234 & 0.921 \\
\hline Lygaeidae & All & 17 & 17 & 2.10 & 5.25 & 0.0375 & 2.065 & 0.861 & 0.1046 & 1.052 & 0.917 \\
\hline Nabidae (Nabis) & All & 17 & 17 & 2.50 & 9.55 & 0.0074 & 2.749 & 0.928 & 0.0855 & 1.255 & 0.952 \\
\hline Miridae & All & 21 & 21 & 2.10 & 4.45 & 0.0353 & 2.185 & 0.666 & 0.0771 & 1.302 & 0.793 \\
\hline Mirid., no Nesiomiris & All & 20 & 20 & 2.10 & 4.45 & 0.0320 & 2.318 & 0.762 & 0.0706 & 1.360 & 0.797 \\
\hline Nabis + Nesiomiris & All & 18 & 18 & 2.50 & 9.55 & 0.0071 & 2.764 & 0.935 & 0.0904 & 1.233 & 0.955 \\
\hline Homoptera & All & 119 & 92 & 1.10 & 8.80 & 0.0234 & 2.536 & 0.846 & 0.0814 & 1.349 & 0.880 \\
\hline Homoptera & Adult & 65 & 64 & 1.60 & 8.80 & 0.0155 & 2.835 & 0.905 & 0.0848 & 1.362 & 0.905 \\
\hline Homoptera & Larvae & 54 & 28 & 1.10 & 5.20 & 0.0585 & 1.670 & 0.627 & 0.0911 & 1.133 & 0.730 \\
\hline Cicadellidae (Nesopbrosyne) & All & 17 & 16 & 3.15 & 5.25 & 0.0067 & 3.141 & 0.884 & 0.0328 & 1.731 & 0.853 \\
\hline Psyllidae + Aphididae & All & 39 & 19 & 1.60 & 3.05 & 0.0175 & 2.629 & 0.839 & 0.0947 & 1.260 & 0.819 \\
\hline Psyllidae & Adult & 26 & 14 & 1.90 & 3.05 & 0.0123 & 2.995 & 0.752 & 0.0778 & 1.592 & 0.800 \\
\hline Fulgoroidea & All & 88 & 73 & 1.10 & 8.80 & 0.0323 & 2.338 & 0.787 & 0.0661 & 1.455 & 0.833 \\
\hline Flatidae (Siphanta acuta) & All & 18 & 18 & 2.45 & 8.80 & 0.0088 & 3.182 & 0.875 & 0.0149 & 2.129 & 0.895 \\
\hline Native Fulgoroidea $^{c}$ & All & 53 & 38 & 1.35 & 5.00 & 0.0511 & 2.072 & 0.809 & 0.1001 & 1.240 & 0.865 \\
\hline Delphacidae & All & 21 & 14 & 1.90 & 3.75 & 0.0206 & 2.764 & 0.668 & 0.0939 & 1.338 & $0.644^{*}$ \\
\hline Cixiidae & All & 24 & 24 & 1.10 & 5.00 & 0.0691 & 1.906 & 0.882 & 0.0966 & 1.246 & 0.923 \\
\hline Lepidoptera & Adult & 9 & 9 & 3.35 & 8.85 & 0.0179 & 2.318 & 0.922 & 0.0873 & 1.184 & 0.961 \\
\hline Lepidoptera & Larvae & 14 & 14 & 4.25 & 16.65 & 0.0271 & 1.769 & 0.683 & 0.0606 & 1.374 & 0.877 \\
\hline
\end{tabular}


TABLE 1 (continued)

\begin{tabular}{|c|c|c|c|c|c|c|c|c|c|c|c|}
\hline \multirow[b]{2}{*}{ Taxon } & \multirow[b]{2}{*}{ Stage } & \multirow[b]{2}{*}{$\mathrm{N}$} & \multirow[b]{2}{*}{$\mathrm{n}$} & \multirow[b]{2}{*}{ Min } & \multirow[b]{2}{*}{$\operatorname{Max}$} & \multicolumn{3}{|c|}{ L Model } & \multicolumn{3}{|c|}{$L * W$ Model } \\
\hline & & & & & & $a$ & $b$ & $R^{2}$ & $a$ & $b$ & $R^{2}$ \\
\hline Diptera & Adult & 30 & 19 & 1.75 & 8.60 & 0.0153 & 2.573 & 0.850 & 0.0756 & 1.338 & 0.939 \\
\hline Collembola & All & 33 & 9 & 1.70 & 3.85 & 0.0056 & 2.809 & 0.924 & 0.0601 & 1.374 & 0.909 \\
\hline Neuroptera & Adult & 8 & 8 & 5.10 & 6.95 & 0.0070 & 2.739 & 0.911 & 0.0521 & 1.467 & 0.891 \\
\hline All holometabolous & Larvae & 23 & 23 & 1.70 & 16.65 & 0.0290 & 1.730 & 0.848 & 0.0534 & 1.387 & 0.919 \\
\hline
\end{tabular}

${ }^{*} 0.001 \leq P \leq 0.005$.

** $P=0.014$

$\ddagger$ No juvenile holometabolous insects (Neuroptera, Coleoptera, Lepidoptera, and Diptera larvae) in these equations.

"Slender beetles include the families Elateridae, Staphylinidae, and Silvanidae.

${ }^{b}$ All weevils include the families Curculionidae, Anobiidae, and Aglycyderidae.

${ }^{c}$ Includes Delphacidae and Cixiidae only; excludes the adventive flatid Sipbanta acuta.

from 0.20 (Diptera: Sciaridae) to $6.45 \mathrm{~mm}$ (Isopoda: Porcellionidae). From these specimens I generated regressions at levels running the gamut from phylum level to single species. For all analyzed groups, I present results from biomass regressions of body length and the product of length and width (Table 1). Attempts to create regressions with body width as a separate parameter were less successful and thus not reported here. To ease comparisons with regressions developed elsewhere, the model parameters are provided in Table 1 and error statistics in Appendix 2.

The logarithmic length-weight regression of all arthropod taxa was highly significant $\left(R^{2}=0.773, P<0.0001\right.$; Figure 1$)$, as was the regression using the product of length and width $\left(R^{2}=0.890, P<0.0001\right.$; Figure $1)$. The parameter $b$, the exponent in the complete power function model, is among the lowest published values for length-only models $(b=2.191)$. Within the most diverse and numerically dominant orders (e.g., Coleoptera, Homoptera), I generated suborder-, family-, and genus-level equations (Table 1; Appendix 2). All equations were highly significant at the alpha level of 0.05 ; most were significant at the 0.001 level. When the testwise alpha is adjusted to an overall alpha of 0.05 by dividing by the number of tests, $92 \%$ of the 50 length regressions and $96 \%$ of the length-width regressions remain significant (test-wise $\alpha=0.001$ ).

Inclusion of width into the predictor variable $x$ often improved the model fit, with some exceptions (Table 1). Incorporating width into the relationship improves the fit in the majority of cases $(36 / 50)$, but often to a negligible extent. Using an arbitrary but more stringent threshold of $5 \%$ change in $R^{2}$, less than half of the relationships (22/50) are improved by incorporating width. Part of this result derives merely from the mathematical constraints of percentages; with an upper limit of $100 \%$, a $5 \%$ improvement is difficult to achieve if the $R^{2}$ is already high. There is, however, a general trend toward more variation explained as taxonomic resolution decreases (Figure 2). The less resolved the taxonomic identity of a specimen, the more informative is the additional variable, body width, toward predicting biomass.

\section{DISCUSSION}

The regression equations presented here provide a tool for the estimation of arthropod biomass in Hawaiian Island ecosystems. Previously, no specific tools were available for Hawaiian arthropods, forcing the use of general relationships constructed for other regions with no shared species. The power $b$ of the length-weight relationship derived for Hawaiian arthropods is among the lowest published (Hódar 1996). This probably is due in part to the selection of specimens used. When I remove holometabolous larvae, predominantly long and thin insects such as caterpillars or lacewing larvae, the power rises to 2.355 (Table 1), closer to the range found 

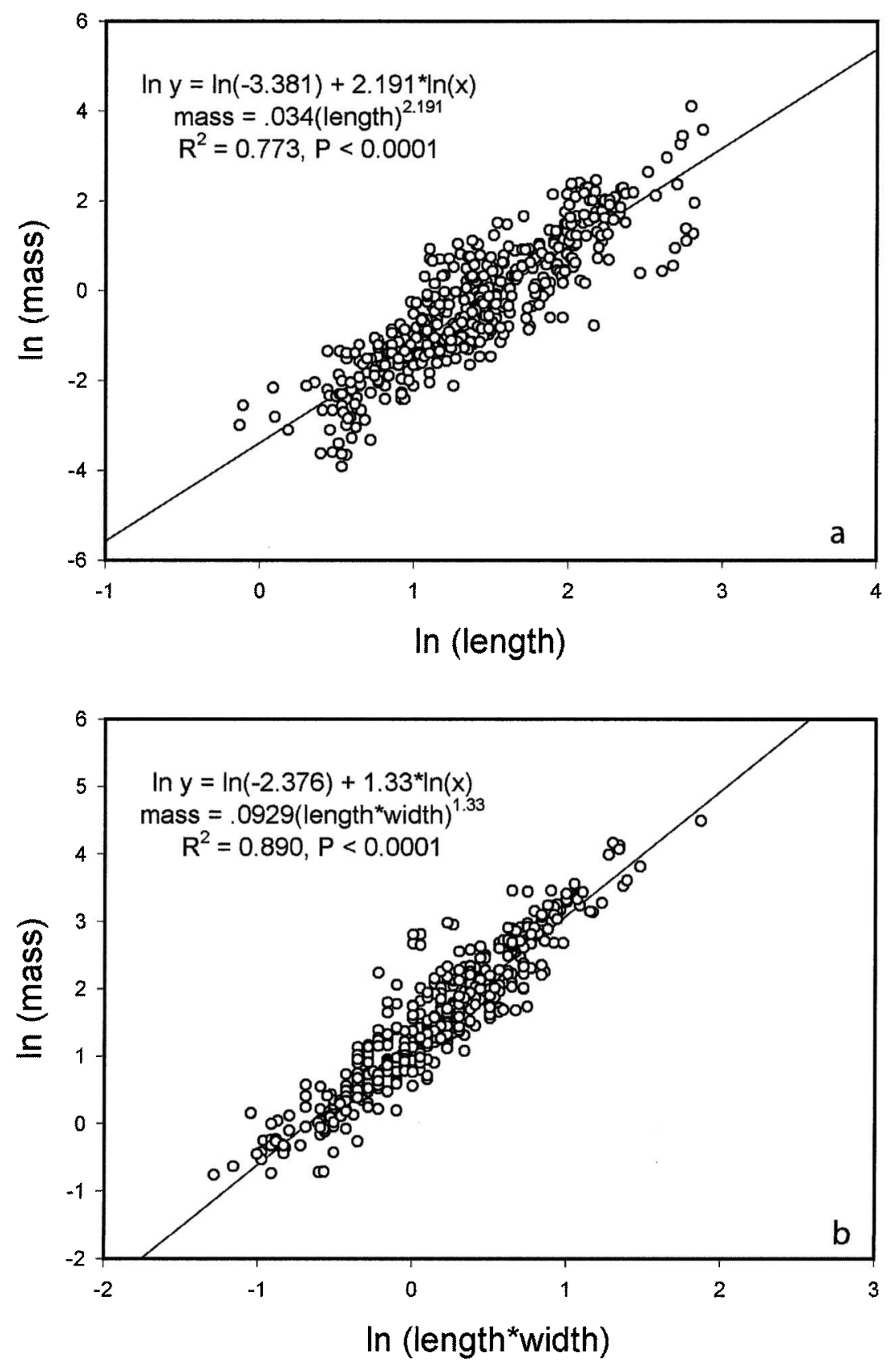

FIGURE 1. General regression relationships of (a) length to dry mass, and (b) the product of length and width to dry biomass. Data are natural log transformed to reduce heteroscedasticity and to linearize the power function for analysis. Regression equations and the back transformation to the power function are given. 


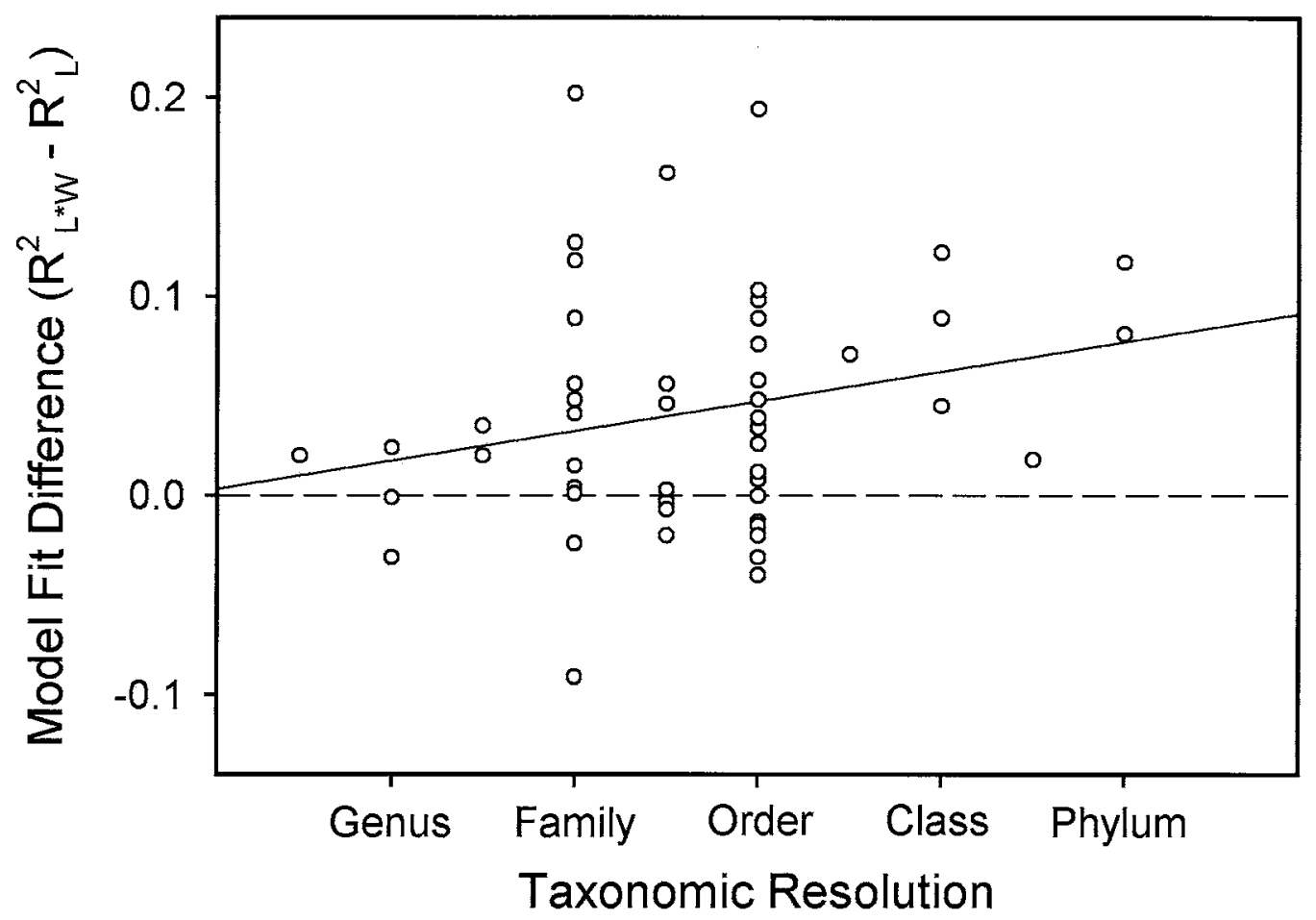

FIGURE 2. Relationship of taxonomic resolution to the relative change in biomass variation explained by length and width $(L * W)$ versus length $(L)$ alone. The dashed line indicates no difference among $R^{2}$ fit estimates. The solid line is a simple linear regression of fit difference on taxonomic resolution, where simple integer scores are given to each taxonomic step. The regression is used to illustrate the visual trend but not intended for formal analysis.

in other studies. Even so, the power is still smaller than the most widely cited, presumably the most-used, general relationship ( $b=2.62$ [Rogers et al. 1976]).

For regressions involving only length, a uniformly proportional series of insects should have a power $b$ in the range of 3 , and 1.5 for regressions involving the product of length and width. General regression equations never have powers that high (Hódar 1996), however, and Schoener (1980) noted that tropical insect groups consistently had a lower power than their temperate counterparts. This is due, in part, to greater preponderance of slender insects such as mantids, phasmids, and Orthoptera in the tropical regions. Although there are no mantids or phasmids in the native Hawaiian fauna, long, slender insects are well represented (e.g.,
Coleoptera: Elateridae, Staphylinidae; Heteroptera: Nabidae, some Miridae). Schoener (1980) suggested that a low $b$ could be considered an "index of bizarreness." For example, model fit for beetles in the family Nitidulidae, although still highly significant for both models, was among the poorest for any group (Table 1). The parameter $b$ is 1.308 for the length model and 1.103 for the model with both length and width. These insects are highly compressed in the unmeasured dimension, height, so length and width together are incomplete predictors of volume. At the other end of the spectrum, the introduced flatid planthopper (Sipbanta acuta) holds its broad triangular forewings vertical, rooflike. Its $b$ value (3.182) is unusually high, again reflecting the inordinate influence of the unmeasured dimension. 
If indeed tropical island insects are less proportional in length and width, there are a number of plausible evolutionary hypotheses that may generate the pattern (Schoener 1980). Predation pressure is hypothesized to be stronger in the Tropics (Dyer and Coley 2001). This may select for cryptic taxa resembling twigs, while also favoring the slender body form of many cursorial predators. The Hawaiian Islands fauna is a product of serendipitous colonization history; perhaps disproportional insects are more suited to long-distance dispersal on the winds and tides? At present, these alternatives cannot be distinguished from random chance. The lesson in the current application is that species in different biogeographic provinces are subject to differing selection pressures and historical contexts. Thus, it is advisable to generate novel location, and possibly habitatspecific, regression relationships if more than the crudest estimates are necessary.

I am aware of no study of arthropod biomass regressions using a randomized series of insects sampled from their environment and measured for this purpose. Thus, there may be biases inherent in the selection of specimens and the relative number representing each taxon. Most of the specimens in this study were obtained through tree canopy collections, although in some communities there are large numbers of mobile soil organisms in the trees (unpubl. data). Highly mobile, nocturnally active, internally phytophagous and epigeal arthropods are probably underrepresented in these samples. Furthermore, the arthropod fauna of the $\mathrm{Ha}$ waiian Islands is highly disturbed or degraded as a result of invasive species or habitat modification (Roderick and Gillespie 1998). Inferences concerning the proportionality of arthropod forms within provincial faunas, and any evolutionary drivers of these patterns, must then be interpreted with caution.

The majority of general relationships, at the phylum, class, and ordinal levels, are improved by incorporating body width into the regressions (Figure 2). The more taxonomically specific the relationship, the trend is toward less improvement in fits using the combination measure. In the more restricted groupings, fits are no different, or usually perform less well, with width included. It is intuitively pleasing that as a group is narrowed and becomes more homogenous, the more informative is length alone. In the $a b$ sence of fine taxonomic resolution, the recommendation would be to measure both length and width and apply general equations. If, however, good identifications are possible, specific equations using only body length will yield biomass estimates qualitatively similar to more detailed equations but with less labor. There are exceptions to this generalization, particularly at the family level, where several fits are dramatically improved with inclusion of width. Closer examination reveals families that are either heterogeneous at the family level (e.g., Heteroptera: Miridae) or else are unusually compressed (e.g., Coleoptera: Nitidulidae) or elongate (e.g., Coleoptera: Ciidae and Scolytidae) in the unmeasured dimension, height.

The development of these equations allows a high predictive capacity for biomass of a broad range of arthropod taxa common in the Hawaiian Islands. Moreover, oceanic islands often share suites of common biotic lineages as a result of their disproportionate colonization abilities over large scales. Highly endemic radiations of birds, land snails, and especially arthropods characterize oceanic island faunas, and many groups typical of continents are absent. Ants and termites, for instance, are entirely absent from the native fauna (Wilson 1996). Small, vagile groups of insects are often found dispersing as aerial plankton on the continents and over the oceans (Holzapfel et al. 1978). These groups are prominent among native Pacific island faunas, along with some relictual taxa no longer present or common on continents (Howarth 1990). Many adventives are widely shared among Pacific islands, whether as a result of the intrinsic affinity of a species for humankind and associated disturbances, or through replicate introductions of biological control agents for pests of widespread commercial crops. Although other authors recommend the independent development and publication of relationships specific to each region or unique habitat (Hódar 1996), these 
equations may be the first choice for other Pacific islands until additional relationships are developed.

\section{ACKNOWLEDGMENTS}

I thank the Division of Forestry and Wildlife of the State of Hawai'i, the U.S. Fish and Wildlife Service, Hawai'i Volcanoes National Park, the Joseph Souza Center at Kōke'e State Park, Parker Ranch, and The Nature Conservancy of Hawai $i$ for access to field sites. D. A. Polhemus, D. Foote, D. Preston, H. Farrington, G. L. Hasty, J. K. Tomberlin, C. Tauber, and J. Rohrer helped to collect or else provided me with specimens; D. Foote and the research staff at Hawaili Volcanoes National Park provided logistical assistance. A. Taylor, C. C. Daehler, and two anonymous reviewers improved the manuscript with their comments.

\section{Literature Cited}

Blackburn, T. M., and K. J. Gaston. 1997. A critical assessment of the form of the interspecific relationship between abundance and body size in animals. J. Anim. Ecol. 66:233-249.

Blackburn, T. M., V. K. Brown, B. M. Doube, J. J. D. Greenwood, J. H. Lawton, and N. E. Stork. 1993. The relationship between abundance and body size in natural animal assemblages. J. Anim. Ecol. 62:519-528.

Brown, J. H., and B. A. Maurer. 1986. Body size, ecological dominance and Cope's rule. Nature (Lond.) 324:248-250.

Brusca, R. C., and G. J. Brusca. 1990. Invertebrates. Sinauer Associates, Sunderland, Massachusetts.

Dawson, J. W., and L. Stemmerman. 1990. Metrosideros (Myrtaceae). Pages 964-970 in W. L. Wagner, D. R. Herbst, and S. H. Sohmer, eds. Manual of the flowering plants of Hawai'i. Bernice P. Bishop Museum Press, University of Hawaiti Press, Honolulu.

Dyer, L. A., and P. D. Coley. 2001. Latitudinal gradients in tri-trophic interac- tions. Pages 67-88 in T. Tscharntke and B. A. Hawkins, eds. Multitrophic level interactions. Cambridge University Press, Cambridge, U.K.

Fretz, J. S. 2000. Relationship of canopy arthropod prey to distribution and life history of the Hawai'i 'akepa. Ph.D. diss., University of Hawai'i at Mānoa, Honolulu.

Gowing, G., and H. F. Recher. 1984. Length-weight relationships for invertebrates from forests in south-eastern New South Wales. Aust. J. Ecol. 9:5-8.

Gruner, D. S., and D. A. Polhemus. In press. Arthropod communities across a long chronosequence in the Hawaiian Islands. Chapter 13 in Y. Basset, V. Novotný, S. E. Miller, and R. L. Kitching, eds. Arthropods of tropical forests: Spatio-temporal dynamics and resource use in the canopy. Cambridge University Press, London.

Hairston, N. G., F. E. Smith, and L. B. Slobodkin. 1960. Community structure, population control, and competition. Am. Nat. 94:421-425.

Hódar, J. A. 1996. The use of regression equations for estimation of arthropod biomass in ecological studies. Acta Oecol. 17:421-433.

19:4 1997. The use of regression equations for the estimation of prey length and biomass in diet studies of insectivore vertebrates. Misc. Zool. 20:1-10.

Holzapfel, E. P., H. B. Clagg, and M. L. Goff. 1978. Trapping of air-borne insects on ships on the Pacific, part 9. Pac. Insects 19:65-90.

Howarth, F. G. 1990. Hawaiian terrestrial arthropods: An overview. Bishop Mus. Occas. Pap. 30:4-26.

Mueller-Dombois, D., and F. R. Fosberg. 1998. Vegetation of the tropical Pacific islands. Springer, New York.

New, T. R. 1998. Invertebrate surveys for conservation. Oxford University Press, New York.

Peck, R. W. 1993. The influence of arthropods, forest structure, and rainfall on insectivorous Hawaiian forest birds. M.S. thesis, University of Hawai'i at Mānoa, Honolulu. 
Roderick, G. K., and R. G. Gillespie. 1998. Speciation and phylogeography of Hawaiian terrestrial arthropods. Mol. Ecol. 7:519-531.

Rogers, L. E., W. T. Hinds, and R. L. Buschbom. 1976. A general weight vs. length relationship for insects. Ann. Entomol. Soc. Am. 69:387-389.

Rogers, L. E., R. L. Buschbom, and C. R. Watson. 1977. Length-weight relationships of shrub-steppe invertebrates. Ann. Entomol. Soc. Am. 70:51-53.

Sage, R. D. 1982. Wet and dry-weight estimates of insects and spiders based on length. Am. Midl. Nat. 108:407-411.

Sample, B. E., R. J. Cooper, R. D. Greer, and R. C. Whitmore. 1993. Estimation of insect biomass by length and width. Am. Midl. Nat. 129:234-240.

Schoener, T. W. 1980. Length-weight regressions in tropical and temperate forestunderstory insects. Ann. Entomol. Soc. Am. 73:106-109.

Southwood, T. R. E. 1960. The abundance of the Hawaiian trees and the number of their associated insect species. Proc. Hawaii. Entomol. Soc. 17:299-303.

Southwood, T. R. E., and P. A. Henderson. 2000. Ecological methods. Blackwell Science Ltd., London.

Stein, J. D. 1983. Insects infesting Acacia koa (Leguminosae) and Metrosideros polymorpha (Myrtaceae) in Hawaii: An annotated list. Proc. Hawaii. Entomol. Soc. 24:305316.

Systat. 2000. Systat data. SPSS Inc., Chicago, Illinois.

Toda, M., and R. L. Kitching. 2002. Forest ecosystems. Pages 27-109 in T. Nakashizuka and N. E. Stork, eds. Biodiversity research methods: IBOY in western Pacific and Asia. Kyoto University Press, Kyoto.

Whittaker, R. J. 1998. Island biogeography: Ecology, evolution and conservation. Oxford University Press, Oxford, U.K.

Wilson, E. O. 1996. Hawaii: A world without social insects. Bishop Mus. Occas. Pap. $45: 3-7$.

Zimmerman, E. C. 1948. Insects of Hawaii: Introduction. University of Hawai'i Press, Honolulu.

\section{Appendix 1}

Collections Data, Arranged Chronologically within Islands, for Specimens Measured for Length, Width, and Dry Biomass (Numbers in Parentheses Indicate the Number of Specimens for Each Locality)

Hawai'i

Hawai'i Volcanoes National Park, junction of Chain of Craters and Hilina Pali Roads, $1030 \mathrm{~m}, 21$ October 1996, pyrethrum canopy fogging of Metrosideros polymorpha, D. Foote, D. S. Gruner, and D. A. Polhemus (39).

Hawaíi Volcanoes National Park, Hilina Pali Road, $945 \mathrm{~m}, 22$ October 1996, pyrethrum canopy fogging of Metrosideros polymorpha, D. S. Gruner and D. A. Polhemus (20).

Hawai'i Volcanoes National Park, escape road, $1300 \mathrm{~m}$, 23 October 1996, pyrethrum fogging of Cibotium spp., D. S. Gruner and D. A. Polhemus (17).

Hawaiti Volcanoes National Park, escape road, $1300 \mathrm{~m}$, 23 October 1996, pyrethrum canopy fogging of Metrosideros polymorpha, D. S. Gruner and D. A. Polhemus (3).

Hawai'i Volcanoes National Park, near research buildings, $1150 \mathrm{~m}, 23$ October 1996, beating vegetation, D. A. Polhemus (30).

Hawai'i Volcanoes National Park, lower Mauna Loa Strip Road, 1280 m, 24 October 1996, pyrethrum canopy fogging, D. Foote, D. S. Gruner, and D. A. Polhemus (51).

Hawai i Volcanoes National Park, Mauna Loa Strip Road, 1310 m, 24 October 1996, pyrethrum canopy fogging, D. Foote, D. S. Gruner, and D. A. Polhemus (5).

Hawaici Volcanoes National Park, upper Mauna Loa Strip Road, Keōmoku lava flow, 1715 m, 24 October 1996, pyrethrum fogging of Dodonaea viscosa, D. Foote, D. S. Gruner, and D. A. Polhemus (18).

Hawai'i Volcanoes National Park, 'Öla'a Forest tract, Wright Road, 1170 m, 25 October 1996, pyrethrum canopy fogging of Metrosideros polymorpha, D. Foote, D. S. Gruner, and D. A. Polhemus (58).

Hakalau National Wildlife Refuge, upper and middle Pua 'Ákala, 23-28 March 1997, malaise traps and clipping foliage of Metrosideros polymorpha, D. S. Gruner, G. L. Hasty, J. Rohrer, J. K. Tomberlin, and M. Wilkinson (64).

Laupāhoehoe Forest Reserve, adjacent Blair Road, 1200 m, 3 June 1997, pyrethrum canopy fogging of Metrosideros polymorpha, D. S. Gruner and D. A. Polhemus (1).

Upper Waiākea Forest Reserve, tree planting road, 1250 m, 17 September 1997, beating of Pipturus albidus, D. S. Gruner (9).

Kohala Forest Reserve, above Hawaíi Preparatory Academy, Kamuela, 12 October 1997, pyrethrum fogging of Metrosideros polymorpba, D. S. Gruner and D. A. Polhemus (17).

Upper Waiākea Forest Reserve, tree planting road, 1200 m, 27 May 1999, beating foliage of Metrosideros polymorpba, D. S. Gruner (102). 
Waiäkea Forest Reserve, Stainback Highway, 200 m, 15 April 2001, hand collecting from fungus, H. Farrington (5).

Adjacent Hawai'i Volcanoes National Park, Thurston Lava Tube area, $1100 \mathrm{~m}, 22$ June 2001, pyrethrum fogging of logs and foliage of Metrosideros polymorpba, D. S. Gruner (65)

Adjacent Hawai $i$ Volcanoes National Park, Thurston Lava Tube area, $1100 \mathrm{~m}, 22$ June 2001, beating of Coprosma spp., D. S. Gruner (22).

Moloka'i

Kamakou Preserve, near Kolekole cabin, 1210 m, 22 October 1997, pyrethrum canopy fogging of Metrosideros polymorpha, D. S. Gruner and D. A. Polhemus (37).
Kamakou Preserve, near Kolekole cabin, 1210 m, 23 October 1997, pyrethrum canopy fogging of Metrosideros polymorpha, D. S. Gruner and D. A. Polhemus (38).

O'ahu

'Ewa Forest Reserve, Hālawa Valley, 300 m, 23 May 1996, malaise traps, D. J. Preston (2).

Kaua'i

Nāpali-Kona Forest Reserve, Alaka'i swamp trail, 1130 $\mathrm{m}, 30$ October 1997, pyrethrum canopy fogging of Metrosideros polymorpha, D. S. Gruner and D. A. Polhemus (16).

\section{Appendix 2}

Regression Statistics for Relationships of Arthropod Length (L) and Length *Width $(\mathrm{L} * \mathrm{~W})$ Regressions on Dry Biomass. Taxa Are Listed as Nested (Indented) Sets, Not Necessarily Reflecting Phylogenetic Distance with Consistent Depth of Indentation. Parameters Apply to the Relation $\ln y=\ln a+b^{*} \ln x$, Where $x$ Is $\mathrm{L}$ or $\mathrm{L} * W$, and $y$ Is Mass. Sample Size, Data Range, and Model Fit Statistics Can Be Found in Table 1. SEE Refers to Standard Error of the Model Fit, and SE Is the Standard Error Estimate for the Subscript Parameters. These Statistics Are Provided for Use in Comparisons with Regression Estimates Elsewhere.

\begin{tabular}{|c|c|c|c|c|c|c|c|c|c|c|c|}
\hline \multirow[b]{2}{*}{ Taxon } & \multirow[b]{2}{*}{ Stage } & \multicolumn{5}{|c|}{ L Model } & \multicolumn{5}{|c|}{$\mathrm{L} \star W$ Model } \\
\hline & & $\mathrm{SEE}$ & $\ln a$ & $\mathrm{SE}_{\ln a}$ & $b$ & $\mathrm{SE}_{b}$ & SEE & $\ln a$ & $S E_{\ln A}$ & $b$ & $\mathrm{SE}_{b}$ \\
\hline Arthropoda & All & 0.661 & -3.381 & 0.080 & 2.191 & 0.054 & 0.446 & -2.376 & 0.039 & 1.330 & 0.022 \\
\hline Arthropoda & $\ddagger$ & 0.61 & -3.549 & 0.077 & 2.355 & 0.053 & 0.461 & -2.344 & 0.041 & 1.323 & 0.023 \\
\hline Insecta & All & 0.67 & -3.353 & 0.083 & 2.173 & 0.057 & 0.467 & -2.386 & 0.040 & 1.333 & 0.022 \\
\hline Insecta & 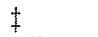 & 0.618 & -3.538 & 0.081 & 2.355 & 0.057 & 0.461 & -2.383 & 0.040 & 1.346 & 0.023 \\
\hline Crustacea & All & 0.416 & -4.280 & 0.298 & 2.669 & 0.163 & 0.367 & -2.644 & 0.178 & 1.322 & 0.071 \\
\hline Isopoda & All & 0.267 & -4.185 & 0.219 & 2.770 & 0.122 & 0.394 & -2.850 & 0.245 & 1.351 & 0.089 \\
\hline Amphipoda & All & 0.129 & -4.732 & 0.189 & 2.682 & 0.101 & 0.188 & -2.627 & 0.166 & 1.419 & 0.078 \\
\hline Arachnida & All & 0.417 & -2.879 & 0.144 & 2.332 & 0.121 & 0.315 & -1.983 & 0.077 & 1.355 & 0.052 \\
\hline Araneae & All & 0.402 & -3.140 & 0.178 & 2.532 & 0.144 & 0.310 & -2.071 & 0.093 & 1.408 & 0.060 \\
\hline Non-Tetragnathidae & All & 0.336 & -3.404 & 0.170 & 2.924 & 0.153 & 0.343 & -2.087 & 0.111 & 1.418 & 0.076 \\
\hline $\begin{array}{r}\text { Tetragnathidae } \\
\text { (Tetragnatba) }\end{array}$ & All & 0.247 & -3.292 & 0.295 & 2.406 & 0.200 & 0.240 & -1.981 & 0.185 & 1.356 & 0.109 \\
\hline Blattodea & All & 0.255 & -3.463 & 0.212 & 2.358 & 0.128 & 0.231 & -2.480 & 0.146 & 1.387 & 0.068 \\
\hline Hymenoptera & Adult & 0.389 & -4.276 & 0.226 & 2.383 & 0.160 & 0.360 & -2.414 & 0.110 & 1.298 & 0.080 \\
\hline Orthoptera & All & 0.395 & -4.017 & 0.370 & 2.720 & 0.191 & 0.324 & -2.097 & 0.195 & 1.325 & 0.075 \\
\hline Psocoptera & All & 0.429 & -4.298 & 0.338 & 3.115 & 0.407 & 0.467 & -2.434 & 0.141 & 1.352 & 0.197 \\
\hline Coleoptera & All & 0.679 & -3.393 & 0.165 & 2.347 & 0.113 & 0.554 & -2.292 & 0.093 & 1.358 & 0.051 \\
\hline Coleoptera & Adult & 0.636 & -3.384 & 0.158 & 2.384 & 0.108 & 0.535 & -2.245 & 0.092 & 1.355 & 0.050 \\
\hline Carabidae & Adult & 0.208 & -4.085 & 0.279 & 2.752 & 0.131 & 0.203 & -2.120 & 0.183 & 1.393 & 0.065 \\
\hline Ciidae + Scolytidae & Adult & 0.375 & -3.464 & 0.339 & 2.531 & 0.457 & 0.258 & -2.223 & 0.095 & 1.480 & 0.169 \\
\hline Ciidae & Adult & 0.36 & -3.701 & 0.426 & 3.102 & 0.664 & 0.234 & -2.168 & 0.092 & 1.637 & 0.209 \\
\hline Coccinellidae & Adult & 0.488 & -2.625 & 0.689 & 2.665 & 0.617 & 0.548 & -1.675 & 0.572 & 1.189 & 0.333 \\
\hline Nitidulidae & Adult & 0.177 & -2.690 & 0.483 & 1.308 & 0.370 & 0.146 & -2.633 & 0.311 & 1.103 & 0.207 \\
\hline (Slender beetles ${ }^{a}$ ) & Adult & 0.331 & -4.282 & 0.234 & 2.595 & 0.138 & 0.319 & -2.215 & 0.131 & 1.213 & 0.062 \\
\hline (All weevils ${ }^{b}$ ) & Adult & 0.442 & -3.473 & 0.206 & 2.641 & 0.147 & 0.456 & -1.993 & 0.135 & 1.379 & 0.079 \\
\hline $\begin{array}{l}\text { Aglycyderidae } \\
\text { (Proterbinus) }\end{array}$ & Adult & 0.116 & -4.002 & 0.126 & 3.144 & 0.123 & 0.119 & -2.044 & 0.055 & 1.481 & 0.060 \\
\hline Anobiidae & Adult & 0.192 & -4.823 & 1.264 & 3.463 & 0.938 & 0.157 & -2.565 & 0.506 & 1.422 & 0.298 \\
\hline Curculionidae & Adult & 0.643 & -2.801 & 0.551 & 2.315 & 0.317 & 0.620 & -1.653 & 0.385 & 1.298 & 0.170 \\
\hline Heteroptera & All & 0.405 & -3.192 & 0.178 & 1.934 & 0.123 & 0.270 & -2.473 & 0.086 & 1.234 & 0.049 \\
\hline Lygaeidae & All & 0.266 & -3.284 & 0.275 & 2.065 & 0.214 & 0.206 & -2.258 & 0.131 & 1.052 & 0.082 \\
\hline Nabidae (Nabis) & All & 0.319 & -4.911 & 0.371 & 2.749 & 0.198 & 0.261 & -2.459 & 0.163 & 1.255 & 0.073 \\
\hline
\end{tabular}


Appendix 2 (continued)

\begin{tabular}{|c|c|c|c|c|c|c|c|c|c|c|c|}
\hline \multirow[b]{2}{*}{ Taxon } & \multirow[b]{2}{*}{ Stage } & \multicolumn{5}{|c|}{ L Model } & \multicolumn{5}{|c|}{$\mathrm{L} * W$ Model } \\
\hline & & SEE & $\ln a$ & $\mathrm{SE}_{\ln a}$ & $b$ & $\mathrm{SE}_{b}$ & SEE & $\ln a$ & $\mathrm{SE}_{\ln a}$ & $b$ & $\mathrm{SE}_{b}$ \\
\hline Miridae & All & 0.666 & -3.344 & 0.401 & 2.185 & 0.355 & 0.313 & -2.563 & 0.202 & 1.302 & 0.153 \\
\hline Mirid., no Nesiomiris & All & 0.338 & -3.443 & 0.343 & 2.318 & 0.306 & 0.312 & -2.651 & 0.219 & 1.360 & 0.162 \\
\hline Nabis + Nesiomiris & All & 0.309 & -4.944 & 0.335 & 2.764 & 0.182 & 0.257 & -2.404 & 0.145 & 1.233 & 0.067 \\
\hline Homoptera & All & 0.469 & -3.756 & 0.149 & 2.536 & 0.114 & 0.414 & -2.508 & 0.085 & 1.349 & 0.052 \\
\hline Homoptera & Adult & 0.397 & -4.165 & 0.163 & 2.835 & 0.117 & 0.397 & -2.467 & 0.099 & 1.362 & 0.056 \\
\hline Homoptera & Larvae & 0.489 & -2.838 & 0.277 & 1.670 & 0.253 & 0.416 & -2.396 & 0.172 & 1.133 & 0.135 \\
\hline Cicadellidae (Nesophrosyne) & All & 0.179 & -5.000 & 0.441 & 3.141 & 0.304 & 0.201 & -3.416 & 0.330 & 1.731 & 0.192 \\
\hline Psyllidae + Aphididae & All & 0.251 & -4.044 & 0.231 & 2.629 & 0.279 & 0.267 & -2.357 & 0.078 & 1.260 & 0.144 \\
\hline Psyllidae & Adult & 0.254 & -4.397 & 0.454 & 2.995 & 0.497 & 0.229 & -2.553 & 0.139 & 1.592 & 0.230 \\
\hline Fulgoroidea & All & 0.492 & -3.434 & 0.204 & 2.338 & 0.144 & 0.436 & -2.717 & 0.139 & 1.455 & 0.077 \\
\hline Flatidae (Sipbanta acuta) & All & 0.504 & -4.730 & 0.513 & 3.182 & 0.301 & 0.462 & -4.206 & 0.421 & 2.129 & 0.183 \\
\hline Native Fulgoroidea $^{c}$ & All & 0.388 & -2.974 & 0.205 & 2.072 & 0.168 & 0.325 & -2.302 & 0.126 & 1.240 & 0.082 \\
\hline Delphacidae & All & 0.423 & -3.883 & 0.612 & 2.764 & 0.563 & 0.438 & -2.366 & 0.329 & 1.338 & 0.287 \\
\hline Cixuidae & All & 0.318 & -2.672 & 0.193 & 1.906 & 0.149 & 0.257 & -2.337 & 0.134 & 1.246 & 0.077 \\
\hline Lepidoptera & Adult & 0.274 & -4.024 & 0.446 & 2.318 & 0.254 & 0.194 & -2.438 & 0.193 & 1.184 & 0.090 \\
\hline Lepidoptera & Larvae & 0.595 & -3.607 & 0.846 & 1.769 & 0.348 & 0.370 & -2.804 & 0.383 & 1.374 & 0.148 \\
\hline Diptera & Adult & 0.56 & -4.180 & 0.396 & 2.573 & 0.262 & 0.356 & -2.582 & 0.152 & 1.338 & 0.082 \\
\hline Collembola & All & 0.287 & -5.177 & 0.282 & 2.809 & 0.304 & 0.314 & -2.811 & 0.105 & 1.374 & 0.164 \\
\hline Neuroptera & Adult & 0.259 & -4.958 & 0.677 & 2.739 & 0.349 & 0.288 & -2.954 & 0.478 & 1.467 & 0.210 \\
\hline All holometabolous & Larvae & 0.501 & -3.540 & 0.340 & 1.730 & 0.160 & 0.366 & -2.930 & 0.203 & 1.387 & 0.090 \\
\hline
\end{tabular}

* No juvenile holometabolous insects (Neuroptera, Coleoptera, Lepidoptera, and Diptera larvae) in these equations.

a Slender beetles include the families Elateridae, Staphylinidae, and Silvanidae.

${ }^{b}$ All weevils include the families Curculionidae, Anobiidae, and Aglycyderidae.

c Includes Delphacidae and Cixiidae only; excludes the adventive flatid Siphanta acuta. 